\title{
Article \\ Rapid Maxillary Expansion in Pediatric Patients with Sleep-Disordered Breathing: Cephalometric Variations in Upper Airway's Dimension
}

\author{
Alessandro Nota ${ }^{1}$ (D), Silvia Caruso ${ }^{2}$, Sara Caruso ${ }^{2}$, Fabio Massimo Sciarra ${ }^{2}$, Alessandra Marino ${ }^{3}$, Sam Daher ${ }^{4}$, \\ Laura Pittari $^{1}$ (D), Roberto Gatto ${ }^{2}$ and Simona Tecco ${ }^{1, * \mathbb{D}}$
}

check for

updates

Citation: Nota, A.; Caruso, S.;

Caruso, S.; Sciarra, F.M.; Marino, A.;

Daher, S.; Pittari, L.; Gatto, R.; Tecco,

S. Rapid Maxillary Expansion in

Pediatric Patients with

Sleep-Disordered Breathing:

Cephalometric Variations in Upper

Airway's Dimension. Appl. Sci. 2022,

12, 2469. https://doi.org/10.3390/

app12052469

Academic Editor: Yong-Deok Kim

Received: 13 January 2022

Accepted: 25 February 2022

Published: 26 February 2022

Publisher's Note: MDPI stays neutral with regard to jurisdictional claims in published maps and institutional affiliations.

Copyright: (C) 2022 by the authors. Licensee MDPI, Basel, Switzerland. This article is an open access article distributed under the terms and conditions of the Creative Commons Attribution (CC BY) license (https:// creativecommons.org/licenses/by/ $4.0 /)$.
1 Dental School, Vita-Salute San Raffaele University, IRCCS San Raffaele Hospital, 20132 Milan, Italy; nota.alessandro@hsr.it (A.N.); laura_pittari@hotmail.it (L.P.)

2 Department of Life, Health and Environmental Science, University of L'Aquila, 67100 L'Aquila, Italy; silvia.caruso@univaq.it (S.C.); saracaruso2704@gmail.com (S.C.); fabiomassimosciarra@gmail.com (F.M.S.); roberto.gatto@univaq.it (R.G.)

3 NESMOS Department, University La Sapienza, 00189 Roma, Italy; alessandra.marino@uniroma1.it

4 Department of Orthodontics, University of Montréal, Montreal, QC H3C 3J7, Canada; dr.samdaher@yahoo.ca

* Correspondence: tecco.simona@hsr.it

\begin{abstract}
Rapid maxillary expansion (RME) is considered an effective treatment in the management of sleep-disordered breathing (SDB) and malocclusions in pediatric patients, not only because it is able to correct the transverse maxillary deficiency, but it also widens the floor of the nasal cavities, leading to a drastic and immediate reduction in air resistance and facilitating a normal nasal breathing pattern. The aim of this study was to evaluate cephalometric changes in the upper airway's dimensions and facial morphology in pediatric SDB patients treated with RME, comparing data with a no-SDB group treated with RME for malocclusion. In this retrospective study, pre-treatment and post-treatment cephalometric variables were measured on lateral skull radiographs from 20 SDB pediatric patients (nine males and 11 females) aged 6 to 9 years (mean age $7.61 \pm 0.6$ ), treated with a rapid maxillary expander, and 20 control patients without SDB (nine males and 11 females) aged 6 to 11 years (mean age $8.4 \pm 0.5$ ). In both groups, there were statistically significant changes in the variables indicating the airway's dimensions and mandibular sagittal position in relation to the cranial base, with a skeletal class II correction in SDB children. Rapid maxillary expansion is associated with an increase in upper-airway dimensions in SDB children, as well as in control healthy subjects, with a possible correction of class II relationship.
\end{abstract}

Keywords: sleep disorders breathing; maxillary expansion; cephalometry; airway obstruction; interceptive orthodontics

\section{Introduction}

Sleep-disordered breathing (SDB) indicates breathing difficulties during sleep time; it is a disorder characterized by prolonged increased upper-airway resistance and partial or complete upper-airway obstruction, which compromise the pulmonary ventilation or the sleep quality [1]. SDB refers to increased upper-airway resistance, from primary snoring to obstructive sleep apnea (OSA) [2,3]. Several studies examined anatomic differences between SDB subjects and healthy nasal breathers using traditional cephalometric tracing, model analysis, and three-dimensional (3D) radiography [3-9]. Guilleminault et al. suggested that children with a high hard palate and long oval-shaped face are highly likely to have sleep-disordered breathing [9]. Model analysis revealed that SDB patients had a narrower maxilla and mandible compared with the control group; the tongue could compensate for the reduced inter-arch dimensions, assuming a more upward and backward position $[7,10,11]$. The most common cause of SDB is adenotonsillar hypertrophy. Children with adenotonsillar hypertrophy are usually treated with adenotonsillectomy, but the 
surgery itself may cause a narrower epipharyngeal air space and a more poorly developed maxilla, which may predispose children to sleep-disordered breathing, with a continuum of severity, varying from snoring to obstructive sleep apnea [12]. For this reason, rapid maxillary expansion (RME) is considered a treatment option as part of an orthodontic procedure for managing this respiratory disorder [13-16], since RME is a painless treatment [17] that can simultaneously correct transverse maxillary deficiency and widen the floor of the nasal cavities. This, in turn, leads to a drastic and immediate reduction in air resistance, facilitating a normal nasal breathing pattern, with possible explanation of the mandibular and hyoid bone advancement, which may explain the anterior traction of the tongue, in turn increasing the posterior dimension of the respiratory tract and reducing its resistance, consequently improving nocturnal breathing quality, while also influencing the periodontal status of mouth breathing subjects [18]. Regarding treatment timing with RME, it has been reported that early mixed dentition is the ideal phase, to prevent subsequent anatomical changes that may later occur in skeletal and soft tissues, such as the stabilization of morphological characteristics of a long and narrow uvula, increase in palatal vault dimensions, presence of a cross or open bite, abnormal position of canines and molars, and generalized crowding $[11,19,20]$. Rapid maxillary expansion in pediatric patients with obstructive sleep apnea is associated with an increase in the maxillary transverse dimension and widening of the nasal cavities, mostly evaluated on 3D analyses [13,16,21,22]. Additional dental effects include uprighting of the maxillary incisors, with a reduction in the angle between the sella-nasion plane and the axis of the upper incisor; moreover, the upper incisors tend to extrude. As a result, cephalometric variations of overbite and overjet can be observed.

Thus, the aim of this study was to evaluate cephalometric variables concerning dentoskeletal changes and airway dimensions in SDB children treated with rapid maxillary expansion, compared with healthy children treated with RME for malocclusion.

\section{Materials and Methods}

\subsection{The Sample}

In this retrospective study, pre-treatment and post-treatment cephalometric variables were measured on lateral skull radiographs from 20 SDB pediatric patients (nine males and 11 females) with mixed dentition, aged between 6 and 9 years (mean age $7.61 \pm 0.6$ ), treated with rapid maxillary expander. All patients were treated in the private orthodontic practice of one of the authors (F.M.S., Teramo, central Italy). Statistical data were compared with a control group of 20 patients without SDB (nine males and 11 females) with mixed dentition, aged between 6 and 11 years (mean age $8.4 \pm 0.5$ ), treated with rapid palatal expansion for their malocclusion, in the same private practice.

The study was conducted in accordance with the Declaration of Helsinki and approved by the Institutional Review Board (or Ethics Committee) of University of L'Aquila (protocol code DR206/2013, dated 10 January 2014). Informed consent was obtained from all subjects involved in the study.

The case inclusion criteria were as follows: (1) clinical history of SDB (episodes of sleep apnea, habitual snoring, and/or states of restlessness during sleep, as reported by parents); (2) patients who achieved considerable clinical improvements of SDB after the orthodontic treatment of maxillary expansion; (3) patients who initially showed a malocclusion with necessity of maxillary expansion (subjects with cross bite or palatal constriction); (4) patients with mixed dentition with erupted permanent central incisors before the beginning of maxillary expansion; (5) patients with treatment performed as described in the next section; (6) patients who had lateral cephalometric radiographs taken before and after rapid maxillary expansion, obtained using the same technique, with a clear visualization of the airways.

Exclusion criteria were as follows: (1) patients with full deciduous dentition; (2) patients previously treated by surgical therapy for SDB (adenoidectomy, tonsillectomy, or adenotonsillectomy); (3) patients with obesity; (4) patients with genetic pathologies related to SDB; (5) patients with craniofacial anomalies and malformations; (6) patients with other 
systemic pathologies, such as cardiorespiratory or neuromuscular disorders, which could affect normal respiration patterns.

\subsection{Rapid Maxillary Expansion}

All patients were treated with rapid maxillary expanders. The orthodontic devices were fixed, with a central expansion screw, and support arms extended to the palatal surfaces of the deciduous canines. The appliance is presented in Figure 1. All patients were treated with the same activation protocol: two daily expansion activations (average number of total activations: $12.1 \pm 1.4$ ), until contact between the palatal cusps of the upper molars and the vestibular cups of the lower molars was achieved. The orthodontic device was removed approximately some months (6-8 months) after the first activation (T1).

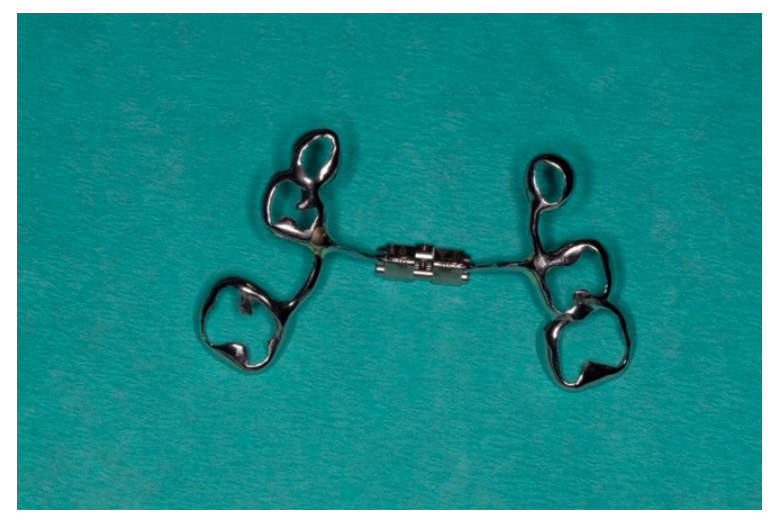

Figure 1. Maxillary expander characterized by the presence of a cast metal framework anchored to one or more deciduous teeth and/or permanent first molars.

\subsection{Cephalometric Tracing and Data Handling}

For all the patients, a cephalometric tracing was performed on the collected lateral skull radiographs, with calculation of the variables described in Table 1. A method study was performed on 10 randomly selected radiographs, repeating the measurements after a few days. For each variable, the difference between the first and second measurement was always less than $5 \%$ of the natural variation of the variable itself. Data were then analyzed to evaluate the distribution. For each variable, descriptive statistics included the mean and standard deviation at baseline T0 and after maxillary expander removal (T1). Then, to evaluate the relationship between the parameters, due to the smaller sample size, a nonparametric test was used. The Wilcoxon signed rank test was used to evaluate changes overtime. StatPlus for Mac v7 (AnalystSoft Inc., Walnut, CA, USA) software was used for all statistical analysis. For each analysis, $p$ was set at the 0.05 level.

Table 1. Cephalometric variables analyzed.

\begin{tabular}{|c|c|}
\hline \multicolumn{2}{|l|}{ Skeletal Variables } \\
\hline SNA (grades) & Angle identified by the points $\mathrm{S}, \mathrm{N}$, and $\mathrm{A}$ \\
\hline SNB (grades) & Angle identified by the points $S, N$, and $B$ \\
\hline ANB (grades) & Difference between SNA and SNB angles \\
\hline SN^GOGN (grades) & Angle identified by the intersection of the S-N and GO-GN planes \\
\hline $\mathrm{FM}^{\wedge}$ (grades) & Angle identified by the intersection of the Frankfurt and mandibular planes \\
\hline $\mathrm{MM}^{\wedge}$ (grades) & Angle identified by the intersection of the bispinal and mandibular planes \\
\hline \multicolumn{2}{|l|}{ Dental variables } \\
\hline OVB (mm) & Vertical distance between the incisal edge of upper and lower incisor \\
\hline
\end{tabular}


Table 1. Cont.

\begin{tabular}{|c|c|}
\hline \multicolumn{2}{|l|}{ Skeletal Variables } \\
\hline OVJ (mm) & Horizontal distance between the incisal edge of upper and lower incisor \\
\hline 1^MAX (grades) & Angle identified by the intersection of the axis of the upper incisor and the bispinal plane \\
\hline 1s-N-FH (mm) & Distance between the upper incisor and the N-FH line (Frankfurt plane) \\
\hline 1i-N-FH (mm) & Distance between the lower incisor and the N-FH line (Frankfurt plane) \\
\hline 1i^MAND (grades) & Angle identified by the intersection of the axis of the lower incisor and the mandibular plane \\
\hline 1s-A-Po $(\mathrm{mm})$ & Distance between the upper incisor and the A-Po line \\
\hline 1i-A-Po (mm) & Distance between the lower incisor and the A-Po line \\
\hline $1 s^{\wedge} 1 \mathrm{i}$ (grades) & Angle identified by the intersection of the axes of the upper and lower central incisors \\
\hline Ul-E-line $(\mathrm{mm})$ & Distance between upper lip (Ul point) and Ricketts's aesthetic line (tip of nose-tip of chin) \\
\hline Ll-E-line (mm) & Distance between upper lip (Ll point) and Ricketts's aesthetic line (tip of nose-tip of chin) \\
\hline \multicolumn{2}{|l|}{$\begin{array}{l}\text { Upper airway space } \\
\text { dimensions }\end{array}$} \\
\hline Nasopharynx (mm) & $\begin{array}{l}\text { Distance from a point on the posterior contour of the soft palate to the point closest to the posterior } \\
\text { wall of the pharynx }\end{array}$ \\
\hline Oropharynx (mm) & $\begin{array}{l}\text { Distance from the intersection of the posterior edge of the tongue and the lower edge of the mandible } \\
\text { to the point closest to the posterior wall of the pharynx }\end{array}$ \\
\hline Hypopharynx (mm) & $\begin{array}{l}\text { Distance from a point on the posterior base of the tongue to the point closest to the posterior wall of } \\
\text { the pharynx }\end{array}$ \\
\hline PNS-P (mm) & Distance between the lowest point of the soft palate $(\mathrm{P})$ and the posterior nasal spine (PNS) \\
\hline MP-H (mm) & Distance between the mandibular plane (MP) and the hyoid bone $(\mathrm{H})$ \\
\hline PH L (mm) & Distance between the base of the epiglottis $(\mathrm{Eb})$ and the tip of the tongue $(\mathrm{Tt})$ \\
\hline
\end{tabular}

\section{Results}

At the end of the treatment, all patients had an improvement in clinical parameters relating to nocturnal breathing (Table 2). Pre-treatment cephalometric data are summarized in Table 3.

Table 2. Clinical conditions associated with the onset of sleep-disordered breathing in the study group, with their frequency.

\begin{tabular}{|c|c|c|c|}
\hline & \multicolumn{3}{|c|}{ Study Group } \\
\hline & T0 & T1 & \\
\hline $\begin{array}{l}\text { Clinical Condition Associated to the Onset of } \\
\text { Sleep-Disordered Breathing }\end{array}$ & $\begin{array}{c}n / 20 \\
(\%)\end{array}$ & $\begin{array}{c}n / 20 \\
(\%)\end{array}$ & $\begin{array}{l}\text { Difference between } \\
\text { T0 and T1 (\%) }\end{array}$ \\
\hline Allergy & $\begin{array}{c}7 / 20 \\
(35)\end{array}$ & $\begin{array}{c}6 / 20 \\
(30)\end{array}$ & -5 \\
\hline Rhinitis & $\begin{array}{c}3 / 20 \\
(15)\end{array}$ & $\begin{array}{c}2 / 20 \\
(10)\end{array}$ & -5 \\
\hline Roncopathy & $\begin{array}{c}8 / 20 \\
(40)\end{array}$ & $\begin{array}{l}3 / 20 \\
(15)\end{array}$ & $-25 *$ \\
\hline Apnea & $\begin{array}{c}12 / 20 \\
(60)\end{array}$ & $\begin{array}{l}6 / 20 \\
(30)\end{array}$ & $-30 *$ \\
\hline Other sleep disorders & $\begin{array}{c}6 / 20 \\
(30)\end{array}$ & $\begin{array}{c}3 / 20 \\
(15)\end{array}$ & $-15^{*}$ \\
\hline
\end{tabular}


Table 3. Initial cephalometric data in the study and the control groups.

\begin{tabular}{|c|c|c|}
\hline Variables & Study Group & Control Group \\
\hline & Mean and SD & Mean and SD \\
\hline \multicolumn{3}{|c|}{ Skeletal variables } \\
\hline SNA & $81.6(3.3)$ & $81.4(1.84)$ \\
\hline SNB & $77.9(3)$ & $78.52(1.77)$ \\
\hline ANB & $4.95(2.1)$ & $3.1(2.05)$ \\
\hline SN^GOGN & $31.5(5)$ & $30.52(3.05)$ \\
\hline $\mathrm{FM}^{\wedge}$ & $24.4(4.2)$ & $24.27(3.02)$ \\
\hline $\mathrm{MM}^{\wedge}$ & $25.3(4.1)$ & $27.22(3.46)$ \\
\hline \multicolumn{3}{|l|}{ Dental variables } \\
\hline OVB & $4.4(1.7)$ & $3.97(1.35)$ \\
\hline OVJ & $5.4(2.1)$ & $4.67(1.91)$ \\
\hline 1^MAX & $112.6(7.6)$ & $111.25(4.25)$ \\
\hline 1s-N-FH & $5.6(4)$ & $3.95(2.94)$ \\
\hline 1i-N-FH & $1.9(3.7)$ & $1.27(2.6)$ \\
\hline 1i^MAND & $93.9(8.2)$ & $93.27(5.15)$ \\
\hline 1s-A-Po & $5.1(4.3)$ & $2.95(4.89)$ \\
\hline 1i-A-Po & $1.3(3.6)$ & $1.67(2.54)$ \\
\hline $1 \mathrm{~s}^{\wedge} 1 \mathrm{i}$ & $128.4(11.4)$ & $131.07(4.64)$ \\
\hline Ul-E-line & $1.75(2.5)$ & $1.05(1.98)$ \\
\hline Ll-E-line & $1(2.8)$ & $0.22(1.88)$ \\
\hline \multicolumn{3}{|c|}{ Upper airway spaces dimensions } \\
\hline Nasopharynx & $11.6(1.8)$ & $11.55(1.88)$ \\
\hline Oropharynx & $10.6(1.6)$ & $9.67(1.33)$ \\
\hline Hypopharynx & $11.1(1.9)$ & $11.67(1.56)$ \\
\hline PNS-P & $35.1(3.4)$ & $36.47(3.4)$ \\
\hline MP-H & $13(1.1)$ & $13.35(1.25)$ \\
\hline PH L & $77.6(5.2)$ & $77(3.22)$ \\
\hline
\end{tabular}

The results of cephalometric changes observed post treatment are reported in Table 4 for the study group and in Table 5 for the control group. In the study group (Table 4), statistically significant changes were mainly found in the variables indicating the size of the airways, while not many other variations were found, except for the sagittal position of the maxilla and mandible in relation to the cranial base (SNA, SNB, and ANB angles). In the control group (Table 5), on the other hand, there were more generalized variations in the craniofacial morphology, compared to the study group, regarding the sagittal and vertical position of the maxilla, the position of the teeth, and the size of the airways.

Table 4. Patients in the study group: cephalometric changes after treatment and statistical analysis results (Wilcoxon signed rank test).

\begin{tabular}{lcccc}
\hline Variables & T0 & T1 & T1 - T0 & Z $(p)$ \\
\hline Skeletal variables & Mean and SD & Mean and SD & Mean and SD & Wilcoxon Test \\
\hline SNA & & & & \\
\hline
\end{tabular}


Table 4. Cont.

\begin{tabular}{|c|c|c|c|c|}
\hline Variables & T0 & T1 & T1 - T0 & $Z(p)$ \\
\hline & Mean and SD & Mean and SD & Mean and SD & Wilcoxon Test \\
\hline SNB & $77.9(3)$ & $79.7(2)$ & $1.8(2.94)$ & $-3.21(0.00)^{* *}$ \\
\hline ANB & $4.95(2.1)$ & $3.3(1.1)$ & $1.62(1.84)$ & $-2.75(0.00)^{* *}$ \\
\hline SN`GOGN & $31.5(5)$ & $31.3(5.1)$ & $0.07(2.74)$ & $-0.22(0.82)$ \\
\hline $\mathrm{FM}^{\wedge}$ & $24.4(4.2)$ & $24.8(4.3)$ & $0.35(2.43)$ & $-1.11(0.26)$ \\
\hline $\mathrm{MM}^{\wedge}$ & $25.3(4.1)$ & $25.7(3.9)$ & $0.45(2.05)$ & $-0.67(0.50)$ \\
\hline \multicolumn{5}{|c|}{ Dental variables } \\
\hline OVB & $4.4(1.7)$ & $3.5(0.9)$ & $0.87(1.39)$ & $-1.83(0.06)$ \\
\hline OVJ & $5.4(2.1)$ & $4.1(1.9)$ & $1.42(2.28)$ & $-0.91(0.35)$ \\
\hline $1^{\wedge} \mathrm{MAX}$ & $112.6(7.6)$ & $112.3(5.8)$ & $0.2(6.33)$ & $-0.22(0.82)$ \\
\hline 1s-N-FH & $5.6(4)$ & $4.9(3.2)$ & $0.5(2.87)$ & $0.00(1.00)$ \\
\hline 1i-N-FH & $1.9(3.7)$ & $1.9(2.8)$ & $0.02(2.04)$ & $0.00(1.00)$ \\
\hline 1i^MAND & $93.9(8.2)$ & $91.1(16.1)$ & $0.3(4.35)$ & $-0.22(1.82)$ \\
\hline 1s-A-Po & $5.1(4.3)$ & $3.7(4.1)$ & $1.07(4.19)$ & $-0.45(0.64)$ \\
\hline 1i-A-Po & $1.3(3.6)$ & $1.1(3.7)$ & $0.2(1.89)$ & $-0.22(0.82)$ \\
\hline $1 \mathrm{~s}^{\wedge} 1 \mathrm{i}$ & $128.4(11.4)$ & $127.8(8)$ & $0.6(6.91)$ & $-0.22(0.82)$ \\
\hline Ls-Le & $1.75(2.5)$ & $2.7(1.8)$ & $1.12(1.81)$ & $-1.64(0.09)$ \\
\hline Li-Le & $1(2.8)$ & $1.3(2.4)$ & $1.05(2.43)$ & $-1.37(0.16)$ \\
\hline \multicolumn{5}{|c|}{$\begin{array}{l}\text { Upper airway spaces } \\
\text { dimensions }\end{array}$} \\
\hline Nasopharynx & $11.6(1.8)$ & $14.1(1.5)$ & $2.52(0.81)$ & $-4.24(0.00)^{* *}$ \\
\hline Oropharynx & $10.6(1.6)$ & $13.4(1.5)$ & $2.87(0.91)$ & $-4.24(0.00)^{* *}$ \\
\hline Hypopharynx & $11.1(1.9)$ & $14.7(5.1)$ & $2.55(1.05)$ & $-4.12(0.00)^{* *}$ \\
\hline PNS-P & $35.1(3.4)$ & $37.5(3.2)$ & $2.42(1.71)$ & $-3.53(0.00)^{* *}$ \\
\hline MP-H & $13(1.1)$ & $14.8(1.3)$ & $1.6(1.41)$ & $-4.24(0.00)^{* *}$ \\
\hline PH L & $77.6(5.2)$ & $80.2(5)$ & $2.72(1.94)$ & $-4.24(0.00) * *$ \\
\hline
\end{tabular}

${ }^{*} p<0.05 ;{ }^{* *} p<0.01$.

Table 5. Control group patients: cephalometric changes after treatment, and statistical analysis results (Wilcoxon signed rank test).

\begin{tabular}{lcccc}
\hline Variable & T0 & T1 & T1 - T0 & Z $(p)$ \\
\hline Skeletal variables & Mean and SD & Mean and SD & Mean and SD & Wilcoxon Test \\
\hline SNA & & & & \\
\hline SNB & $81.4(1.84)$ & $81.2(1.28)$ & $0.2(1.38)$ & $-1.15(0.25)$ \\
\hline ANB & $78.52(1.77)$ & $79.72(1.24)$ & $1.2(2.37)$ & $-2.90(0.00)^{* *}$ \\
\hline SN`GOGN $^{\wedge}$ & $3.1(2.05)$ & $1.87(1.2)$ & $1.22(2.26)$ & $-1.94(0.05)^{*}$ \\
\hline FM $^{\wedge}$ & $30.52(3.05)$ & $30.92(2.48)$ & $0.37(1.74)$ & $-1.13(0.26)$ \\
\hline MM $^{\wedge}$ & $24.27(3.02)$ & $25.02(2.69)$ & $0.75(1.56)$ & $-2.16(0.03)^{*}$ \\
\hline Dental variables & $27.22(3.46)$ & $28.05(2.96)$ & $0.87(1.31)$ & $-2.31(0.02)^{*}$ \\
\hline OVB & & & & \\
\hline
\end{tabular}


Table 5. Cont.

\begin{tabular}{lcccc}
\hline Variable & T0 & T1 & T1 - T0 & Z $(p)$ \\
\hline Mean and SD & Mean and SD & Mean and SD & Wilcoxon Test \\
\hline 1^MAX & $4.67(1.91)$ & $3.72(0.88)$ & $0.95(1.55)$ & $-2.51(0.01)^{*}$ \\
\hline 1s-N-FH & $111.25(4.25)$ & $111.7(3.12)$ & $1.2(4.14)$ & $-0.24(0.80)$ \\
\hline 1i-N-FH & $3.95(2.94)$ & $3.32(2.36)$ & $0.47(1.14)$ & $-2.51(0.01)^{*}$ \\
\hline 1i^MAND & $1.27(2.6)$ & $0.9(1.8)$ & $0.37(1.21)$ & $-1.47(0.14)$ \\
\hline 1s-A-Po & $93.27(5.15)$ & $92.35(3.1)$ & $0.97(3.04)$ & $-1.30(0.19)$ \\
\hline 1i-A-Po & $2.95(4.89)$ & $1.55(3.79)$ & $1.45(1.7)$ & $-2.83(0.00)^{* *}$ \\
\hline 1s^1i & $1.67(2.54)$ & $1.1(2.31)$ & $0.57(1.32)$ & $-1.83(0.07)$ \\
\hline Ul-E-line & $131.07(4.64)$ & $131.57(3.24)$ & $0.5(3.1)$ & $-0.5(0.61)$ \\
\hline Ll-E-line & $1.05(1.98)$ & $2.17(1.87)$ & $1.07(1.09)$ & $-3.38(0.00)^{* *}$ \\
\hline Upper airway spaces & $0.22(1.88)$ & $1.12(1.85)$ & $0.85(0.85)$ & $-3.31(0.00)^{* *}$ \\
\hline dimensions & & & & \\
\hline Nasopharynx & $11.55(1.88)$ & $12.05(1.54)$ & $0.55(0.62)$ & $-2.95(0.00)^{* *}$ \\
\hline Oropharynx & $9.67(1.33)$ & $10.4(1.17)$ & $0.72(0.59)$ & $-3.44(0.00)^{* *}$ \\
\hline Hypopharynx & $11.67(1.56)$ & $11.67(1.88)$ & $0.5(0.53)$ & $-0.22(0.82)$ \\
\hline PNS-P & $36.47(3.4)$ & $36.85(4.06)$ & $0.87(0.68)$ & $-2.7(0.00)^{* *}$ \\
\hline MP-H & $13.35(1.25)$ & $14.2(1.23)$ & $0.85(0.56)$ & $-3.59(0.00)^{* *}$ \\
\hline PH L & $77(3.22)$ & $77.65(2.83)$ & $0.65(0.63)$ & $-3.21(0.00)^{* *}$ \\
\hline${ }^{*} p 0.05 ; * * 0.01$. & & &
\end{tabular}

\section{Discussion}

This retrospective study in a pediatric population was aimed at reporting changes in cephalometric variables after rapid maxillary expansion orthodontic treatment in subjects affected by OSA and in control healthy children. In both groups, statistically significant increases were observed regarding the parameters relating to the airway dimension, such as width of the pharyngeal spaces. In the study group, before the treatment, the mean cephalometric values for nasopharyngeal, oropharyngeal, and hypopharyngeal spaces were $11.6 \mathrm{~mm}( \pm 1.8), 10.6 \mathrm{~mm}( \pm 1.6)$, and $11.1 \mathrm{~mm}( \pm 1.9)$, respectively. After the treatment, averages of $14.1 \mathrm{~mm}( \pm 1.5), 13.4 \mathrm{~mm}( \pm 1.5)$, and $14.7 \mathrm{~mm}(5.1)$ were observed. Therefore, a statistically significant increase in values was recorded (nasopharynx: $z=-4.24$, $p=0.00$; oropharynx: $z=-4.24, p=0.00$; hypopharynx: $z=-4.12, p=0.00)$. In the control healthy group, statistically significant changes were also observed in the nasopharynx and oropharynx; before treatment, the mean cephalometric values for nasopharyngeal and oropharyngeal spaces were $11.55 \mathrm{~mm}( \pm 1.88)$ and $9.67 \mathrm{~mm}( \pm 9.33)$, respectively, whereas averages of $12.05 \mathrm{~mm}( \pm 1.54)$ and $10.04( \pm 1.17)$ were observed following orthodontic therapy. Therefore, a statistically significant increase in values was recorded (nasopharynx: $z=-2.95, p=0.00$; oropharynx: $z=-3.44, p=0.00$ ). These results confirm that maxillary expansion induces an increase in the width of the airways.

In comparison with the literature, Taddei et al. [13] showed no significant changes in the pharyngeal spaces following rapid maxillary expansion, but it is important to mention that the Taddei study consisted of a sample of children affected by Marfan syndrome (a total of 30 children, aged 8 to 10 years). Moreover, all their Marfan patients initially presented a skeletal class II (ANB $>4^{\circ}$ ), and the treatment time (active and passive phases) was between 3 and 9 months. We, therefore, attribute the difference between our results and the Taddei results to the difference in sample selection criteria between both studies. 
Another study, by Pavoni et al. [23], reported significant changes in the upper airway dimensions in a sample of skeletal class II patients with SDB, using a different type of orthodontic device, whereby the patients were treated with a functional appliance aimed at mandibular advancement. In addition, their median follow-up period was 20 months. That device also included a maxillary expansion screw, which was activated once a month; therefore, another important difference with our study was that they obtained a dentoalveolar expansion, rather than a skeletal expansion. Post treatment, Pavoni et al. observed a reduction in SDB, a reduction in the size of adenoids, an increase in pharyngeal width, and a forward relocation of the tongue and the hyoid bone in relation to the mandibular base. Lastly, they also recorded an improvement in skeletal class II cephalometric parameters, specifically, the ANB angle. Thus, it can be said these studies confirm that the expansion of the upper arch, even if dentoalveolar, increases the width of the airways.

Regarding the skeletal class (ANB angle) cephalometric improvement, while pretreatment study subjects revealed an ANB angle of on average $4.95^{\circ}\left( \pm 2.1^{\circ}\right)$, i.e., skeletal class II, the post-treatment average value was reduced to $3.3^{\circ}\left( \pm 1.1^{\circ}\right)$, i.e., to class I, with a statistically significant reduction $(z=-2.75 ; p=0.00)$. In our study, before treatment, 13 out of 20 patients had a skeletal class II relationship (ANB $>4^{\circ}$ ), while, after treatment, nine of them showed a class I ANB value. Thus, four subjects remained in class II even after treatment. In the literature, the correction of skeletal class requests a treatment based on a mandibular advancement [24]. Correction of the skeletal class was associated with a greater advancement of the mandible compared to the maxilla, although, in both dental arches, there was a statistically significant increase at T1. In reviewing the literature, it can be observed that, in patients with skeletal class II treated with rapid maxillary expansion, correction of class II does not always occur. For example, Lione et al. observed no class II correction in their sample of 30 children treated with both types of rapid palatal expander (banded or bonded), but respiratory function was neither considered nor included in their study [25]. Similarly, in a study by Villa et al. [19], following orthodontic treatment in conjunction with rapid maxillary expansion, no significant changes were found in the cephalometric values concerning the skeletal class II; after a 12 month treatment, the cephalometric analysis did not show significant changes in the SNA, SNB, and ANB angles, whether in patients with resolution of sleep breathing disorders following the orthodontic therapy carried out or in those who still exhibited SDB post orthodontic treatment, although the latter group of patients, with residual sleep-disordered breathing, showed larger ANB values in comparison with those who showed a resolution of the aforementioned condition, without a statistically significant difference between the two groups. It should be noted that the age of the patients in Villa's study ranged from 4 to 10 years, including patients in deciduous dentition. Thus, from data by Villa et al. and from the present sample, it can be concluded, on the basis of Villa's data and corroborated by our data, that pediatric patients with skeletal class II and affected by SDB can experience a skeletal class normalization after a maxillary rapid expansion.

In the present investigation, the study subjects did not show many other cephalometric variations, except for the sagittal position of the maxilla and the mandible in relation to the anterior skull base (the variables SNA, SNB, and ANB angles) (Table 4). In contrast to the control subjects (Table 5), it seems that patients with SDB showed greater changes in airway dimensions after treatment, as could be expected in a group of subjects with increased airway resistance after orthopedic maxillary treatment. In the study group, the changes were limited to the sagittal relationship of the maxillaries with the cranial base (Table 4). In contrast, in the control group (Table 5), there were general variations to the craniofacial morphology, with respect to the sagittal and vertical positions of the jaws, the position of the teeth, and the size of the airways. The difference between the two groups could be related to their initial facial typology, because, at T0, the two groups effectively showed some differences in the patients' facial morphology (Table 3) (for example, for the skeletal class relationship, the inclination of upper and lower incisors, overjet, and overbite). Nonetheless, orthodontists should note that less striking cephalometric changes 
are obtained when treating children with SDB with RME than in children without SDB, concerning dental variables and vertical variables.

The present study was limited to a two-dimensional evaluation. No volumetric evaluations were calculated. Although previous studies stated a positive effect of rapid palatal expansion on expanding the volume of the nasal cavity and the upper part of the upper airway spaces (nasopharynx and oropharynx increase) [22], three-dimensional diagnostic techniques are not a routine exam in the pediatric population, even for SDB, while cephalometry was demonstrated to be a standardized and relatively simple radiologic technique to evaluate anatomical craniofacial relationships. Two-dimensional routine cephalometry has been in use for a long time in orthodontics, but it is now gradually being introduced in SBD treatment to envisage an optimal treatment selection, as well as to predict treatment outcomes [26]. In addition, this study was limited to a short-term follow-up and to a small study group, and further evaluations will be needed to investigate long-term changes in the sample.

\section{Conclusions}

Rapid maxillary expansion is associated with an increase in airway dimensions in children with sleep breathing disorders, as well as in control patients. In patients with skeletal class II and sleep-disordered breathing, a skeletal class II correction after rapid maxillary expansion could be observed, due to a mandibular advancement. While no other significant changes in facial morphology were observed in SDB patients, healthy subjects experienced more statistically significant cephalometric changes regarding mandibular divergence and dental variables.

Author Contributions: Conceptualization, F.M.S., A.N., S.C. (Silvia Caruso) and S.T.; methodology, F.M.S., S.C. (Silvia Caruso) and S.T.; software, S.T.; validation, S.T., S.C. (Silvia Caruso) and A.N.; formal analysis, A.N. and S.T.; investigation, F.M.S., S.C. (Silvia Caruso), L.P. and S.T.; resources, A.M., S.C. (Sara Caruso) and S.T.; data curation, A.N. and S.T.; writing-original draft preparation, A.N., F.M.S., S.C. (Sara Caruso), S.C. (Silvia Caruso) and S.T.; writing-review and editing, A.N., S.D., L.P. and S.T.; supervision, R.G. and S.T. All authors have read and agreed to the published version of the manuscript.

Funding: This research received no external funding.

Institutional Review Board Statement: The study was conducted in accordance with the Declaration of Helsinki and approved by the Institutional Review Board (or Ethics Committee) of the University of L'Aquila (protocol code DR206/2013, dated 10 January 2014).

Informed Consent Statement: Informed consent was obtained from all subjects involved in the study.

Data Availability Statement: Data are available upon request via email to the corresponding author.

Conflicts of Interest: The authors declare no conflict of interest.

\section{Abbreviations}

SDB: sleep-disordered breathing; OSA: obstructive sleep apnea; RME: rapid maxillary expansion (RME).

\section{References}

1. Carroll, J.L. Obstructive sleep-disordered breathing in children: New controversies, new directions. Clin. Chest. Med. 2003, 24, 261-282. [CrossRef]

2. Nazarali, N.; Altalibi, M.; Nazarali, S.; Major, M.P.; Flores-Mir, C.; Major, P.W. Mandibular advancement appliances for the treatment of paediatric obstructive sleep apnea: A systematic review. Eur. J. Orthod. 2015, 37, 618-626. [CrossRef]

3. Pracharktam, N.; Hans, M.G.; Strohl, K.P.; Redline, S. Upright and supine cephalometric evaluation of obstructive sleep ap-nea syndrome and snoring subjects. Angle Orthod. 1994, 64, 63-73. [PubMed]

4. Mayer, G.; Meier-Ewert, K. Cephalometric predictors for orthopaedic mandibular advancement in obstructive sleep apnoea. Eur. J. Orthod. 1995, 17, 35-43. [CrossRef] [PubMed]

5. Tangugsorn, V.; Skatvedt, O.; Krogstad, O.; Lyberg, T. Obstructive sleep apnoea: A cephalometric study. Part II. Uvuloglossopharyngeal morphology. Eur. J. Orthod. 1995, 17, 57-67. [CrossRef] 
6. Cozza, P.; Ballanti, F.; Prete, L. A modified monoblock for treatment of young children with obstructive sleep apnea. J. Clin. Orthod. 2004, 38, 241-247.

7. Lione, R.; Buongiorno, M.; Franchi, L.; Cozza, P. Evaluation of maxillary arch dimensions and palatal morphology in mouthbreathing children by using digital dental casts. Int. J. Pediatr. Otorhinolaryngol. 2014, 78, 91-95. [CrossRef]

8. Iwasaki, T.; Takemoto, Y.; Inada, E.; Sato, H.; Saitoh, I.; Kakuno, E.; Kanomi, R.; Yamasaki, Y. Three-dimensional cone-beam computed tomography analysis of enlargement of the pharyngeal airway by the Herbst appliance. Am. J. Orthod. Dentofac. Orthop. 2014, 146, 776-785. [CrossRef]

9. Guilleminault, C.; Pelayo, R.; Leger, D.; Clerk, A.; Bocian, R.C.Z. Recognition of Sleep-disordered Breathing in Children. Pediatrics 1996, 98, 871-882. [CrossRef]

10. Baroni, M.; Ballanti, F.; Franchi, L.; Cozza, P. Craniofacial features of subjects with adenoid, tonsillar, or adenotonsillar hypertrophy. Prog. Orthod. 2011, 12, 38-44. [CrossRef]

11. Marino, A.; Nota, A.; Caruso, S.; Gatto, R.; Malagola, C.; Tecco, S. Obstructive sleep apnea severity and dental arches dimen-sions in children with late primary dentition: An observational study. CRANIO 2021, 39, 225-230. [CrossRef] [PubMed]

12. Villa, M.P.; Bernkopf, E.; Pagani, J.; Broia, V.; Montesano, M.; Ronchetti, R. Randomized Controlled Study of an Oral JawPositioning Appliance for the Treatment of Obstructive Sleep Apnea in Children with Malocclusion. Am. J. Respir. Crit. Care Med. 2002, 165, 123-127. [CrossRef]

13. Taddei, M.; Alkhamis, N.; Tagariello, T.; D’Alessandro, G.; Mariucci, E.M.; Piana, G. Effects of rapid maxillary expansion and mandibular advancement on upper airways in Marfan's syndrome children: A home sleep study and cephalometric evaluation. Sleep Breath. 2015, 19, 1213-1220. [CrossRef] [PubMed]

14. Huynh, N.T.; Desplats, E.; Almeida, F.R. Orthodontics treatments for managing obstructive sleep apnea syndrome in chil-dren: A systematic review and meta-analysis. Sleep Med. Rev. 2016, 25, 84-94. [CrossRef] [PubMed]

15. Júnior, A.J.M.; Zancanella, E.; Crespo, A. Rapid maxillary expansion and obstructive sleep apnea: A review and meta-analysis. Med. Oral. Patol. Oral. Cir. Bucal. 2016, 21, e465-e469. [CrossRef]

16. Hoxha, S.; Kaya-Sezginer, E.; Bakar-Ates, F.; Köktürk, O.; Toygar-Memikoğlu, U. Effect of semi-rapid maxillary expansion in children with obstructive sleep apnea syndrome: 5-month follow-up study. Sleep Breath. 2018, 22, 1053-1061. [CrossRef]

17. Libonati, A.; Nardi, R.; Gallusi, G.; Angotti, V.; Caruso, S.; Coniglione, F.; Marzo, G.; Mattei, A.; Tecco, S.; Paglia, L.; et al. Pain and anxiety associated with Computer-Controlled Local Anaesthesia: Systematic review and meta-analysis of cross-over studies. Eur. J. Paediatr. Dent. 2018, 19, 324-332. [CrossRef]

18. Mummolo, S.; Tieri, M.; Nota, A.; Caruso, S.; Darvizeh, A.; Albani, F.; Gatto, R.; Marzo, G.; Marchetti, E.; Quinzi, V.; et al. Salivary concentrations of Streptococcus mutans and Lactobacilli during an orthodontic treatment. An observational study comparing fixed and removable orthodontic appliances. Clin. Exp. Dent. Res. 2020, 6, 181-187. [CrossRef]

19. Villa, M.P.; Rizzoli, A.; Rabasco, J.; Vitelli, O.; Pietropaoli, N.; Cecili, M.; Marino, A.; Malagola, C. Rapid maxillary expansion outcomes in treatment of obstructive sleep apnea in children. Sleep Med. 2015, 16, 709-716. [CrossRef]

20. Mummolo, S.; Nota, A.; De Felice, M.E.; Marcattili, D.; Tecco, S.; Marzo, G. Periodontal status of buccally and palatally im-pacted maxillary canines after surgical-orthodontic treatment with open technique. J. Oral. Sci. 2018, 27, 552-556. [CrossRef]

21. Caprioglio, A.; Meneghel, M.; Fastuca, R.; Zecca, P.A.; Nucera, R.; Nosetti, L. Rapid maxillary expansion in growing patients: Correspondence between 3-dimensional airway changes and polysomnography. Int. J. Pediatr. Otorhinolaryngol. 2014, $78,23-27$. [CrossRef] [PubMed]

22. Niu, X.; Di Carlo, G.; Cornelis, M.A.; Cattaneo, P.M. Three-dimensional analyses of short- and long-term effects of rapid maxillary expansion on nasal cavity and upper airway: A systematic review and meta-analysis. Orthod. Craniofacial Res. 2020, 23, 250-276. [CrossRef] [PubMed]

23. Pavoni, C.; Cretella Lombardo, E.; Lione, R.; Bollero, P.; Ottaviani, F.; Cozza, P. Orthopaedic treatment effects of functional therapy on the sagittal pharyngeal dimensions in subjects with sleep-disordered breathing and Class II malocclusion. Acta Otorhinolaryngol. Ital. 2017, 37, 479-485. [CrossRef]

24. Caruso, S.; Nota, A.; Severino, M.; Gatto, R.; Meuli, S.; Mattei, A.; Tecco, S. Mandibular advancement with clear aligners in the treatment of skeletal Class II. A retrospective controlled study. Eur. J. Paediatr. Dent. 2021, 22, 26-30. [CrossRef] [PubMed]

25. Lione, R.; Brunelli, V.; Franchi, L.; Pavoni, C.; Quiroga Souki, B.; Cozza, P. Mandibular response after rapid maxillary expansion in class II growing patients: A pilot randomized controlled trial. Prog. Orthod. 2017, 18, 36. [CrossRef]

26. Denolf, P.L.; Vanderveken, O.M.; Marklund, M.E.; Braem, M.J. The status of cephalometry in the prediction of non-CPAP treatment outcome in obstructive sleep apnea patients. Sleep Med. Rev. 2016, 27, 56-73. [CrossRef] 